\title{
Processamento de artigos para terapia ventilatória: revisão da literatura nacional
}

\author{
Ventilatory therapy processing supplies: a review of the Brazilian literature \\ Procesamiento de artículos para terapia ventilatoria: revisión de la literatura brasileña
}

Maria Valdenice Lopes dos Santos ${ }^{1}$, Janaína Anchieta Costa²

\begin{abstract}
RESUMO: Objetivo: buscar as evidências do processamento de artigos de terapia ventilatória nas publicações nacionais de Enfermagem. Método: estudo de levantamento bibliográfico, com recorte temporal de dez anos, nas bases de dados LILACS, MEDLINE, BDENF e SciELO, em que foram analisados seis artigos científicos e 12 manuais técnicos. Resultados: tanto a literatura nacional quanto os manuais técnicos publicados recomendam, para o processamento dos artigos de assistência ventilatória, a realização da limpeza, seguida da desinfecção de alto nível pelo calor úmido em temperaturas superiores a $70{ }^{\circ} \mathrm{C}$, pelo período de 30 minutos; a esterilização a vapor saturada sob pressão para os artigos termorresistentes ou a esterilização à baixa temperatura para os artigos termossensíveis. Conclusão: dado o número reduzido de publicações sobre o tema, as informações colhidas nos revelaram a necessidade de um melhor controle dos processos de limpeza e termodesinfecção, uma vez que as tecnologias disponíveis nos permitem chegar a um índice relevante no impacto da qualidade e da segurança do material processado.
\end{abstract}

PALAVRAS-CHAVE: Infecção hospitalar. Desinfecção. Nebulizadores e vaporizadores. Trato respiratório. Esterilização.

ABSTRACT: Objective: This study aimed to search for evidence of ventilatory therapy processing supplies in national nursing publications. Method: A literature review with time frame of ten years was carried out at LILACS, MEDLINE, SciELO and BDENF database, where six scientific articles and 12 technical manuals were analyzed. Results: Both the national literature and the technical manuals published recommend that ventilatory assistance processing supplies undergo cleaning followed by high level disinfection by humid heat at temperatures over $70{ }^{\circ} \mathrm{C}$ for 30 minutes; under-pressure steam saturated sterilization for thermoresistent supplies, or low temperature sterilization for thermosensitive supplies. Conclusion: Given the reduced number of publications on the subject, the information collected shows the need for a better control of the processes of cleaning and thermal disinfection, since the technologies available allowed us to reach a relevant level on the impact on the quality and safety of the material processed.

KEYWORDS: Nosocomial infection. Disinfection. Nebulizers and vaporizers. Respiratory tract. Sterilization.

RESUMEN: Objetivo: Buscar las evidencias del procesamiento de artículos de terapia ventilatoria en las publicaciones nacionales de enfermería. Método: Estudio de búsqueda bibliográfica, con horizonte temporal de diez años, en las bases de datos LILACS, MEDLINE, SciELO y BDENF, donde se analizaron seis artículos científicos y 12 manuales técnicos. Resultados: Tanto la literatura nacional como los manuales técnicos publicados recomiendan, para el procesamiento de artículos de asistencia ventilatoria, después de terminar la limpieza, la desinfección de alto nivel a través del calor húmedo en temperaturas superiores a $70{ }^{\circ} \mathrm{C}$ durante un periodo de 30 minutos; recomiendan, para artículos termorresistentes, la esterilización por vapor saturado bajo presión; y recomiendan, para artículos termosensibles, la esterilización a baja temperatura. Conclusión: Dado el reducido número de publicaciones sobre el tema, la información recogida nos revela la necesidad de un mejor control de los procesos de limpieza y desinfección térmica, ya que las tecnologías disponibles nos permiten llegar a un ratio relevante en el impacto de la calidad y seguridad del material procesado.

PALABRAS CLAVE: Infección hospitalaria. Desinfección. Nebulizadores y vaporizadores. Tracto respiratório. Esterilización.

${ }^{1}$ Enfermeira. Graduada. Universidade de Guarulhos (UNG). Especialista em CC, RA e CME. Enfermeira do CME do Hospital São Paulo HU/UNIFESP. Rua do Camutim, 108. CEP 02253-020. Vila Gustavo. São Paulo, SP, Brasil.

Telefone: (11) 5576-4550. E-mail: walcc@hotmail.com

${ }^{2}$ Enfermeira. Mestre em Enfermagem. Escola de Enfermagem (EE). Universidade de São Paulo (USP). Docente. Curso de Graduação em Enfermagem. Universidade Federal de São Paulo (UNIFESP). Enfermeira do CME do Hospital São Paulo HU/UNIFESP. E-mail: janaina@usp.br 


\section{Introdução}

A prevenção e o controle das Infecções Relacionadas à Assistência à Saúde (IRAS) representam um grande desafio a ser superado por todos os profissionais envolvidos na assistência ao paciente, desde aqueles que administram os serviços de saúde até os prestadores de cuidados assistenciais.

A preocupação com o impacto das IRAS, nas condições gerais e de recuperação dos clientes - o que compromete diretamente a qualidade do cuidado oferecido, bem como os custos associados ao aumento no período de internação e os gastos com os tratamentos necessários ao restabelecimento da saúde dos pacientes - tem norteado estudos em busca de soluções para prevenir e controlar as infecções no âmbito hospitalar.

Neste sentido, a prática do processamento de artigos de terapia ventilatória, embora esteja descrita com pouca frequência na literatura, torna-se relevante, uma vez que as infecções associadas à ventilação mecânica têm alcançado números expressivos nas instituições hospitalares ${ }^{1}$.

Estudos realizados no Estado de São Paulo, no ano de 2008, evidenciaram que a média de incidência de Pneumonia Associada à Ventilação Mecânica (PAVM) foi de 16,25 casos por 1.000 dias de uso de ventilador em Unidades de Terapia Intensiva (UTI) de adultos, mas alcançou até 21,06 casos por 1.000 dias de uso de ventilador em Unidades de Terapia Intensiva coronarianas. Estes números sugerem que o índice nacional pode ser ainda mais elevado do que o desejado, uma vez que não há dados nacionais, por falta de uma coleta sistemática e padronizada em todos os Estados ${ }^{1,2}$.

A mortalidade global nos episódios de PAVM varia de 20 a $60 \%$, refletindo, em grande parte, a severidade da doença de base destes pacientes, a falência de órgão e as especificidades da população estudada e do agente etiológico envolvido. Embora essa infecção apresente resultados diversos nos diferentes estudos, aproximadamente $33 \%$ dos pacientes com PAVM morrem em decorrência direta do desenvolvimento deste tipo de infecção ${ }^{1}$.

Além da mortalidade, o impacto da PAVM representa prolongamento da hospitalização, em torno de 12 dias, e aumento de custos, em torno de 40 mil dólares por episódio ${ }^{1}$.

Os pacientes internados e, especialmente, os pacientes em ventilação mecânica, pertencem a um grupo de risco aumentado para pneumonia. Este risco maior se deve, essencialmente, a três fatores: diminuição das defesas do paciente, risco elevado de ter as vias aéreas inoculadas com grande quantidade de material contaminado e presença de microrganismos mais agressivos e resistentes aos antimicrobianos encontrados no ambiente hospitalar e nos materiais utilizados no cuidado com o paciente ${ }^{1}$.

Neste sentido, entende-se que um dos fatores que podem contribuir para a aquisição de pneumonia hospitalar está associado ao inadequado processamento dos artigos de terapia ventilatória ${ }^{2,3}$.
Essa categoria de artigos envolve uma variedade enorme de materiais processáveis, incluindo: nebulizadores, umidificadores, ambus, circuitos de anestesia e circuitos de equipamentos para suporte ventilatório, como também máscaras e conexões com importante utilização na terapia respiratória. Esses materiais têm a finalidade de introduzir líquidos e/ou gases em forma de micropartículas, que são inaladas, atingindo as vias aéreas e possibilitando, assim, o alívio de processos inalatórios, conjuntivos e obstrutivos ${ }^{4}$.

Diante da importância do adequado processamento dos artigos de assistência ventilatória e da relação desta prática - quando não realizada apropriadamente, pode comprometer a qualidade da assistência prestada aos pacientes, principalmente nas UTI -, surgiu a motivação para realização do presente estudo.

\section{Objetivo}

Investigar como estão descritos os procedimentos na literatura nacional e em manuais técnicos publicados, no que se refere ao processamento dos materiais de assistência ventilatória.

\section{Método}

Trata-se de um estudo de revisão da literatura, com a finalidade de obter dados que traduzam a prática do processamento de artigos de assistência ventilatória, buscando responder a questão: Como está descrita a prática do processamento de artigos para a terapia ventilatória em publicações nacionais?

O levantamento bibliográfico foi realizado inicialmente nas seguintes bases de dados: Literatura Latino-Americana e do Caribe em Ciências da Saúde (LILACS), Medical Literature Analisys and Retrietal System Online (Medline), Base de Dados de Enfermagem (BDENF) e, ainda, no recurso eletrônico Sientific Eletronic Library Online (SciELO). $\mathrm{O}$ recorte temporal foi de dez anos, sendo o período compreendido entre 2002 e 2012, por meio de busca online na Biblioteca Virtual em Saúde (BVS), disponível no site: http://www.bireme.br/php/index.php.

Para realizar a busca dos artigos nas bases de dados selecionadas, foi necessário consultar os Descritores de Ciências em Saúde (DeCS), com o objetivo de identificar a terminologia adequada, ou seja, uma terminologia que oferecesse segurança quanto aos resultados encontrados sobre o tema pesquisado.

Ao verificar que não existe um descritor específico para desinfecção de artigos, o levantamento bibliográfico foi realizado, inicialmente, nas bases de dados selecionadas por meio do método de busca por palavras com os termos 'Desinfecção' × 'Artigos'. Desta forma, foram encontradas 27 publicações na base de dados LILACS e uma na MEDLINE. Utilizando-se a palavra 'Inaloterapia', 
encontramos nove publicações na base LILACS e dois artigos na MEDLINE.

Com a finalidade de melhorar a estratégia de busca, outras buscas por palavras foram realizadas nas mesmas bases de dados, utilizando-se as palavras 'Reprocessamento' × 'Material', tendo sido encontradas dez publicações na base de dados LILACS. Na sequência, optou-se por utilizar a expressão 'Centro de Material e Esterilização', sendo encontradas 58 publicações na base de dados LILACS e seis artigos na MEDLINE.

Ao realizar as buscas na base de dados BDENF, constatouse que as publicações encontradas já estavam incluídas nas buscas realizadas anteriormente.

Para alcançar o objetivo proposto nesta pesquisa, foi realizada a leitura do título e do resumo de cada artigo encontrado frente à pergunta norteadora.

\section{Resultados}

Ao totalizar o número de publicações encontradas, excluindo-se os artigos mencionados repetidamente nas bases e aqueles com ano de publicação fora do período estipulado, foram obtidos 113 registros, sendo 104 na LILACS e nove na MEDLINE.

Para a amostra final, foram selecionados seis artigos encontrados nas buscas realizadas, além de 12 manuais técnicos publicados na área de Central de Material e Esterilização, que também foram consultados. Assim, a amostra foi constituída por 18 artigos, conforme consta no Quadro 1.

Quadro 1. Distribuição dos artigos científicos encontrados no estudo, segundo bases de dados.

\begin{tabular}{|c|c|c|c|}
\hline $\begin{array}{c}\text { Base de } \\
\text { dados }\end{array}$ & $\begin{array}{c}\text { Artigos } \\
\text { encontrados }\end{array}$ & $\begin{array}{c}\text { Artigos } \\
\text { selecionados }\end{array}$ & $\begin{array}{c}\text { Artigos utilizados } \\
\text { como amostra }\end{array}$ \\
\hline MEDLINE & 09 & 06 & - \\
\hline LILACS & 104 & 07 & 06 \\
\hline BDENF & - & - & - \\
\hline SciELO & - & - & - \\
\hline Total & $\mathbf{1 1 3}$ & $\mathbf{1 3}$ & $\mathbf{0 6}$ \\
\hline
\end{tabular}

Quadro 2. Classificação dos produtos de assistência ventilatória e processamento para cada tipo de artigo.

\begin{tabular}{|l|l|}
\hline \multicolumn{1}{|c|}{ Classificação e definição dos artigos } & \multicolumn{1}{|c|}{ Recomendações de processamento } \\
\hline $\begin{array}{l}\text { Produtos de assistência respiratória classificados como artigos } \\
\text { críticos: tubos endotraqueais e traqueostomias. }\end{array}$ & Estes produtos devem ser obrigatoriamente descartados após o uso. \\
\hline $\begin{array}{l}\text { Produtos de assistência respiratória classificados como artigos } \\
\text { semicríticos: nebulizadores, umidificadores, inaladores e circuitos } \\
\text { respiratórios. }\end{array}$ & Estes produtos devem passar por desinfecção de alto nível. \\
\hline $\begin{array}{l}\text { Produtos de assistência respiratória classificados como artigos não } \\
\text { críticos: termômetros axilares e oxímetros de pulso. }\end{array}$ & $\begin{array}{l}\text { Estes produtos exigem, como procedimento mínimo, a limpeza e a } \\
\text { desinfecção de baixo nível. }\end{array}$ \\
\hline
\end{tabular}

Fonte: Agência Nacional de Vigilância Sanitária (ANVISA) ${ }^{1}$.

De acordo com a classificação dos artigos segundo o risco potencial de contaminação proposto por Spaulding, os artigos de terapia ventilatória são denominados de artigos semicríticos, considerando-se o risco de infecção. Para os produtos para a saúde classificados como semicríticos, é exigida a desinfecção de alto nível, devido ao contato com mucosas íntegras e colonizadas.

A desinfecção dos produtos para saúde é o processo que elimina a maioria ou todos os microrganismos patogênicos, exceto os esporos bacterianos, em objetos e artigos inanimados; classifica-se esse processo, de acordo com o seu espectro de ação, como alto, intermediário e de baixo nível ${ }^{5}$.

No entanto, o Manual do Trato Respiratório da Agência Nacional de Vigilância Sanitária (ANVISA) ${ }^{1}$ classifica artigos de assistência ventilatória, de acordo com o tipo de processamento, em artigos críticos, semicríticos e não críticos; a ANVISA ainda determina, a partir dessa classificação, a conduta para o processamento desses materiais, conforme os resultados apresentados no Quadro 2.

\section{Discussão}

No processamento dos artigos de assistência ventilatória, a literatura nacional e os manuais técnicos publicados sobre o tema recomendam a realização da limpeza e, em seguida, a desinfecção de alto nível pelo calor úmido em temperaturas superiores a $70^{\circ} \mathrm{C}$ por 30 minutos ou a esterilização a vapor saturado sob pressã $0^{5-7}$.

Os artigos de assistência ventilatória, até pouco tempo atrás, eram processados por meio de desinfecção química. A utilização desse processo sempre despertou discussões associadas à preocupação dos Enfermeiros atuantes em Centro de Material e Esterilização (CME) em relação aos danos causados aos profissionais de saúde na manipulação do glutaraldeído, agente químico comumente empregado. A sua utilização pode causar irritação respiratória, odor pungente e irritante, dermatite de contato alérgica e agressão ao meio ambiente. Além disso, os processos de desinfecção com a utilização de agente químico são de difícil controle ${ }^{8}$. Diante dos riscos apontados, principalmente vinculados à manipulação do glutaraldeído pelos profissionais da saúde, percebeu-se a necessidade de rever a forma de desinfecção 
dos artigos nas instituições de saúde e de se monitorarem, com maior rigor, as etapas deste processo, ${ }^{9,10}$.

A Resolução da Diretoria Colegiada da Agência Nacional de Vigilância Sanitária (ANVISA) RDC nº 15 , de 15 de março de 2012, estabelece que os produtos para a saúde classificados como semicríticos devem ser submetidos, minimamente, ao processo de desinfecção de alto nível, após a limpeza, ou ao processo físico de termodesinfecção ${ }^{11}$.

A primeira etapa e a mais importante do processamento dos artigos de assistência à saúde é a limpeza, pois possibilita a redução da carga microbiana de tais artigos. Assim, é necessário que seja feita de maneira rigorosa e meticulosa, e para os artigos de assistência ventilatória, deve ser realizada em lavadoras termodesinfectadoras ${ }^{12}$.

A termodesinfecção dos artigos é uma inovação tecnológica no CME, devido à realização da limpeza simultânea, que favorece a padronização do processo, otimiza o serviço e reduz os riscos para os trabalhadores. O ciclo é composto por pré-lavagem, lavagem, enxague, termodesinfecção e secagem automática. No último enxague, recomenda-se que seja utilizada água deionizada ou osmose reversa $^{12}$

Os artigos respiratórios são confeccionados por diferentes tipos de componentes materiais. Assim, a escolha do processo, seja de desinfecção, seja de esterilização, também deve considerar a compatibilidade do artigo com esses processos.

Dentre os artigos mais utilizados na terapia ventilatória, encontram-se os dispositivos para macro e micronebulização terapêuticos à base de oxigênio e/ou ar estéril medicinal, procedimento comumente denominado de inaloterapia ou oxigenoterapia. Estes produtos são confeccionados em material plástico termossensível, sendo, após o uso, submetidos aos processos de limpeza e desinfecção ${ }^{13}$.

Os materiais termossensíveis, como os dispositivos para macro e micronebulização, não são compatíveis com a esterilização em alta temperatura em autoclave a vapor saturado sob pressão. Para esses materiais, a alternativa seria a esterilização em equipamentos à baixa temperatura.

A Associação Brasileira de Enfermeiros de Centro Cirúrgico, Recuperação Anestésica e Centro de Material (SOBECC) recomenda, para os analisadores de oxigênio, os cabos e as lâminas do laringoscópio, e a máscara facial de ventilação, a realização da limpeza e, após este processo, proceder à desinfecção com álcool a 70\%7 .

Para os circuitos tubulares, traqueias, extensões de silicone e fios-guia, a recomendação é que seja realizada a limpeza e, posteriormente, a esterilização por vapor saturado, uma vez que a confecção desses artigos permite que sejam submetidos à alta temperatura. Atualmente, o custo de aquisição desses produtos pelas instituições de saúde é bem mais acessível e, por se tratar de artigos que são confeccionados de material não rugoso, são produtos de fácil limpeza, além de sua confecção de silicone permitir que sejam submetidos à alta temperatura ${ }^{14}$.
A literatura também recomenda que os artigos tubulares, como as extensões de borracha ou látex, devem ser limpos com jatos de água após o uso para evitar o ressecamento da matéria orgânica na luz do tubo; note-se que a confecção em silicone transparente destes materiais favorece a checagem da limpeza, contribuindo para o controle de qualidade do processamento desses produtos ${ }^{15}$.

Vale ressaltar que a maioria dos equipamentos de limpeza e termodesinfecção atualmente disponíveis no mercado agrega o uso de alta tecnologia na execução dos processos, tanto de limpeza, quanto de termodesinfecção; esses equipamentos oferecem, assim, às CME, segurança e qualidade no processamento dos artigos de assistência ventilatória, uma vez que há preocupação, por parte dos fabricantes destes equipamentos, com o alcance dos parâmetros recomendados para a eficácia dos processos, a padronização dos procedimentos realizados nesses equipamentos, a documentação dos processos e a diminuição do risco ocupacional de ordem biológica e ambiental ${ }^{8,12}$.

Um sistema de registro dos processos executados possibilita o acompanhamento de todas as fases do processo de limpeza e desinfecção, contribuindo significativamente para identificação de falhas em cada uma das etapas, sendo um importante instrumento de validação ${ }^{12}$.

É consenso na literatura que o controle de qualidade do processamento de artigos de assistência ventilatória somente é obtido a partir do monitoramento das etapas que envolvem a limpeza, a termodesinfecção e a esterilização. A segurança do processamento dos artigos de assistência à saúde nas instituições hospitalares é uma medida importante para o controle de infecção e, baseando-se nas evidências, muito se discute sobre a forma centralizada nos $\mathrm{CME}^{16}$. Estudos mostram que há considerável diminuição de contaminação em uma unidade de central de material quando esta se mostra centralizada, visto que a forma descentralizada, para qualquer que seja o tipo do produto para a saúde, pode comprometer a qualidade do processo ${ }^{17}$.

\section{Conclusão e considerações finais}

A análise dos seis artigos e dos 12 manuais técnicos permitiu atingir o objetivo proposto nesta revisão de literatura.

Verificou-se que a diversificação dos artigos de assistência ventilatória é muito abrangente e, por isso, sugere-se a definição do melhor processo para cada tipo de artigo. Considera-se, assim, o material de constituição dos mesmos e, principalmente, a escolha do processo que assegurará a qualidade da assistência e a segurança do paciente contra o risco de aquisição de IRAS.

Além disso, é muito importante considerar a padronização dos procedimentos e o estabelecimento das rotinas operacionais no processamento dos artigos de assistência ventilatória, de acordo com as evidências encontradas 
na literatura, para a efetivação das melhores práticas no processamento destes artigos.

Este trabalho deve envolver toda a equipe multiprofissional, além da Comissão de Controle de Infecção Hospitalar $(\mathrm{CCIH})$, com o objetivo de acompanhar o resultado do processamento de cada material, potencializando a interação e a organização do trabalho no âmbito hospitalar.

$\mathrm{O}$ estudo proposto advém do interesse em buscar a prática do processamento de artigos de terapia ventilatória. Espera-se que o diagnóstico aqui realizado sirva de subsídio para os Enfermeiros de CME desempenharem importante papel na divulgação e na confecção de novos protocolos, e na validação do processo para futuras ações gerenciais, abrangendo uma assistência qualificada e comprometida com o cliente.

É fundamental, ainda, que o Enfermeiro do CME saiba lidar com a questão do processo do desempenho da sua função, no que tange aos aspectos éticos, à capacitação técnica, aos custos e benefícios, e à multiprofissionalidade, uma vez que esta unidade requer, do profissional Enfermeiro, conhecimentos gerenciais e técnico-administrativos, ao lidar com a coordenação da produção de material e, indiretamente, com a coordenação do processo do cuidar.

\section{Referências}

1. Brasil. Ministério da Saúde - MS. Agência Nacional de Vigilância Sanitária - ANVISA. Manual do trato respiratório: orientações para prevenção de Infecção Relacionada à Assistência à Saúde - IRAS [Internet]. Brasília; out. 2009 [acesso em 2012 Nov 17]. Disponível em: www.anvisa.gov.br/servicosaude/controle/manual \%20 trato_respirat $\%$ F3rio.pdf.

2. Brasil. Ministério da Saúde - MS. Agência Nacional de Vigilância Sanitária - ANVISA. Comissão de Controle de Infecção Hospitalar-CCIH [Internet]. Brasília; 2002 [acesso em 2012 Nov 17]. Disponível em: www.anvisa.gov.br/faqdinamica/index.asp.

3. Secretaria de Estado da Saúde de São Paulo. Divisão de Infecção Hospitalar. Centro de Vigilância Epidemiológica. Manual de avaliação da qualidade de práticas de controle de infecção hospitalar. São Paulo; 2006.

4. Arai LAC, Azevedo RB. Contaminação do aparelho de anestesia por agentes patógenos. Rev. Bras. Anestesiol. 2011;61(1):54-9.

5. Graziano UK, Silva A, Psaltikids EM. Enfermagem em centro de material e esterilização. Barueri: Manole; 2011.

6. Associação Paulista de Epidemiologia e Controle de Infecção Relacionada à Assistência à Saúde - APECIH. Limpeza, Desinfecção e Esterilização de artigos em serviços de saúde. São Paulo: APECIH; 2010.

7. Associação Brasileira de Enfermeiros de Centro Cirúrgico, Recuperação Anestésica e Centro de Material e Esterilização - SOBECC. Práticas recomendadas SOBECC: centro de material e esterilização, centro cirúrgico e recuperação pós-anestésica. 6. ed. São Paulo: SOBECC; 2013.

8. Brasil. Ministério da Saúde - MS. Agência Nacional de Vigilância Sanitária - ANVISA. Informe Técnico n ${ }^{\circ} 04 \backslash 07$. Glutaraldeido em estabelecimento de assistência à saúde. Diário Oficial da República Federativa do Brasil; Brasília; mar. 2007.

9. Secretaria de Saúde do Estado de São Paulo. Resolução SS n ${ }^{\circ} 27$, de 28 de Fevereiro de 2007. Referente às medidas do controle sobre o uso de produtos químicos nos Estabelecimentos Assistenciais de Saúde [Internet]. 2007 [acesso em 2012 Nov 19]. Disponível em: http:// pegasus.fmrp.usp.br/projeto/legislacao/SS-27-REP_280207.pdf.

10. Santana CR, Dominciano LCC, Santos MCC. Avaliação da utilização, manipulação e descarte do glutaraldeído pela equipe de enfermagem em Instituições de Saúde Pública e Privada. Rev Inst Ciênc Saúde [Internet]. 2009 [acesso em 2012 Nov 19];27(4):338-44. Disponível em: http://www3.unip.br/ comunicacao/publicacoes/ics/edicoes/2009/04_out_dez/V27_ n4_2009_p338-344.pdf

11. Brasil. Ministério da Saúde - MS. Agência Nacional de Vigilância Sanitária - ANVISA. Resolução da Diretoria Colegiada RDC $\mathrm{N}^{\circ} 15$, de 15 de março de 2012. Dispõe sobre requisitos de boas práticas para o processamento de produtos para saúde e dá outras providências. Diário Oficial da República Federativa do Brasil; Brasília; mar. 2012.

12. Bergo MCNC. Avaliação do desempenho da limpeza e desinfecção das máquinas lavadoras desinfectadoras automáticas em programas com diferentes tempo e temperaturas. Rev Latino-am Enfermagem [Internet]. 2006 [acesso em 2012 Maio 12];14(5):735-41. Disponível em: file://C:/Users/webdev73/Downloads/23563403-1-PB.pdf

13. Griep R, Picolli M. Validação dos processos de limpeza e desinfecção de artigos de inaloterapia e oxigenoterapia. Cogitare Enferm. 2002;7(2):65-73.

14. Andres PS, Tipple AFV, Candé TA, Barros CA, Miranda PV, Pimenta FC. Tubo de látex: esterilidade pós-reprocessamento em vapor saturado sob pressão. Rev Eletr Enf [Internet]. 2009 [acesso em 2012 Mar 16];11(2):280-5. Disponível em: http://www.fen.ufg. br/revista/v11/n2/v11n2a07.htm

15. Candé TA, Tipple AFV, Mendonça KM, Souza ACS, Miranda PV, Pimenta FC. Influência da limpeza na esterilidade de tubos de silicone: estudo quase experimental. Online Braz J Nurs [Internet]. 2011 [acesso em 2012 Mar 16];10(3):1-15. Disponível em: http:// www.objnursing.uff.br/index.php/nursing/article/view/3696

16. Anders PS, Tipple AFV, Pimenta FC. Kits para aerossol em um serviço de saúde: uma análise microbiológica após reprocessamento. Rev Esc Enferm USP [Internet]. 2008 [acesso em 2012 Jun 4];42(2):276-81. Disponível em: http://www.scielo. $\mathrm{br} / \mathrm{pdf} /$ reeusp/v42n2/a09.pdf

17. Pereira LV, Alves JR, Oliveira AG, Pereira GA, Morais CA. Processamento de máscaras para aerossóis: comparação entre os sistemas centralizado e descentralizado. Nursing (São Paulo). 2002;5(51):15-9. 